\title{
Probing the thermal history of UHT metamorphism through rare earth elements in zircon
}

E. BLEREAU1,2*,P.D. KINNY1, R.J.M. TAYLOR1,3, T. E JOHnSOn1, C. Clark1, E. SANSOM1, M. HAND 4

1 The Institute for Geoscience Research (TIGeR), School of Earth and Planetary Sciences, Curtin University, Perth, Western Australia (eleanore.blereau@gmail.com)

2 John de Laeter Centre, Curtin University, Perth, Western Australia

3 Carl Zeiss Microscopy Ltd, Camborne, Cambridge, United Kingdom

4 Department of Earth Science, University of Adelaide, Adelaide, South Australia

In order to investigate the extent to which volume diffusion can modify rare earth element abundance signatures of accessory minerals during high-temperature metamorphism, we conducted numerical models of the diffusion of REE in zircon under different temperature-time $(T-t)$ conditions. The modelling shows that under short-lived UHT conditions (e.g. $\sim 1100^{\circ} \mathrm{C}$ for $1-5 \mathrm{Myr}$ ) diffusion is sufficiently rapid for $\mathrm{REE}$ in igneous zircon to fully equilibrate with the new metamorphic mineral assemblage. In contrast, at temperatures below $900^{\circ} \mathrm{C}$ (recrystallised) zircon will largely retain its original REE composition, with little modification, even when the thermal event is long lived ( $\geq 100 \mathrm{Myr}$ ). Hence, the diffusion rates of REE in zircon are highly sensitive to the maximum temperature experienced during UHT metamorphism. In situations where volume diffusion is the dominant process, i.e. fluid-absent, this sensitivity can be used to help constrain a $T-t$ path for a high-grade metamorphic terrane independent of whole-rock phase equilibria modelling. We apply the modelling to wellcharacterised natural samples from the regional aureole surrounding the Rogaland Igneous Complex (RIC) in SW Norway, providing additional constraints on the $T$ $t$ conditions of contact metamorphism and the nature of emplacement of the RIC. 